\title{
New Lives, New Landscapes. Landscape, Heritage and Rural Revitalisation: Whose Cultural Values?
}

\author{
Ken Taylor \\ College of Arts and Social Sciences, Australian National University, Canberra, Australia \\ Email:k.taylor@anu.edu.au
}

\begin{abstract}
Worldwide interest in the cultural landscape concept-covering rural and urban spheres-is now a major theme in considerations of the management of cultural heritage places. The roots of this interconnection lie in the social, political and economic relationships between people and landscape which, in turn, is related to how human attachment to landscape plays a major role in determining our sense of place. Notably the fundamental actuality of place attachment through landscape is cross cultural. Epistemologically it crosses the boundaries of differing values across diverse cultures underscoring the fundamental cross cultural significance of landscape. Coincidentally the phenomenon of the 'rise of cultural landscapes' (Jacques 1995) has been intimately interconnected with the way in which thinking has changed - philosophically and professionally —on what heritage is. There is in effect a clear link between heritage and landscape. It is in this context that this paper addresses challenges of thinking and acting associated with China's commitment to a rural revitalisation program.
\end{abstract}

KEYWORDS landscape, culture, heritage, identity, authenticity, rural revitalisation, tourism, traditional villages.

Received May 27, 2019; accepted June 6, 2019.

\section{Contextual Theme}

We should never tinker with the landscape without thinking of those who live in the midst of it.

- J. B. Jackson (1963)

The conference ${ }^{1}$ brief in presenting this paper was to address aspects of heritage conservation within the purview of rural revitalisation in China. The topic reminded me of a 1970 British book New Lives, New Landscapes by Nan Fairbrother in which she addresses inherent heritage values of the British rural landscape. Alongside economic, political and social factors driving rural change, she tracks landscape changes due to pressures for increased food production, mass car ownership, spreading suburbanisation and from rural depopulation ${ }^{2}$. The concept of linking lives to landscape in the book title is one that I find profoundly compelling, particularly through the contextual theme of the inseparable link between landscape setting (countryside), villages and people (Figure 1). It is this contextual theme that is central to my paper with some emphasis on landscape - the cultural landscape - as the setting for people's everyday lives, their activities, memories and sense of identity and hence intangible associative meanings and heritage values that landscape invokes. Identity is a key word, crucial to a sense of place where the tangible (physical features and functions) and intangible (meaning or symbols) coalesce.

The places we inhabit are marked by distinctive characteristics. These are tangible, as in the physical patterns and components of our surrounds, and intangible as in the symbolic meanings and values we attach to places, and also to objects and to traditional ways of expression as in language, art, song, dance etc. In this way physical spaces, sites and objects become places in the wider cultural landscape setting. They offer a past, are part of the present and suggest future continuity. It is these places with their association of meanings which give rise to local identity and sense of place of communities as modelled in Figure 2.

I am conscious of the fact that heritage concerns are but one aspect of China's rural revitalisation dynamic, which, perforce engages with political, social, and economic dimensions as well as cultural dimensions of which cultural heritage considerations are a part. Whilst my comments focus on the cultural heritage dimension, they must be 

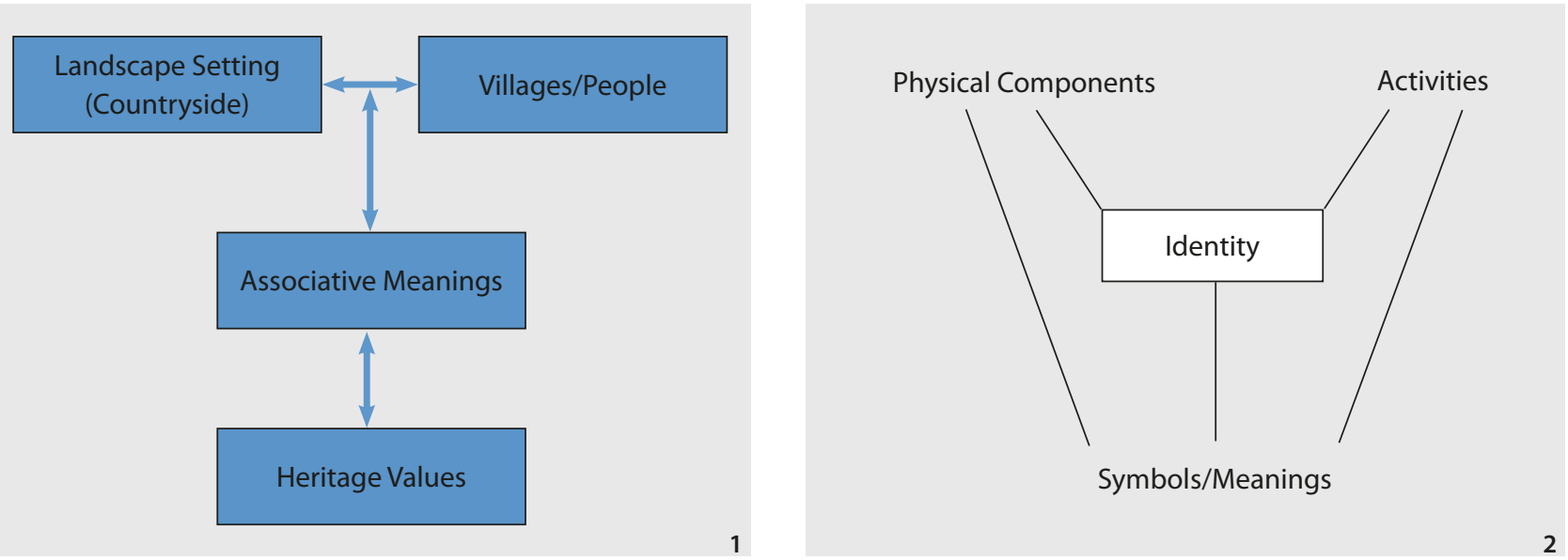

Figure 1 Contextual theme: inseparable link between landscape setting (countryside), villages and people (Source: the author).

Figure 2 Place identity and its components (Source: Relph 2008).

seen in the context of major agricultural and land reform as a critical driver of China's rural revitalisation strategy (Mulholland 2018). Here critical factors, of which I concentrate on 5 and 6 , include:

1. Need to increase food production for the domestic market;

2. Poverty alleviation;

3. Ameliorating rural migration to urban centres;

4. Land reform policy;

5. Traditional village rejuvenation through rural tourism, thereby reshaping rural identity;

6. Increased attention given to historically and culturally significant villages which has led to tourism-based traditional village revitalisation models related to goals of sustainable rural development and poverty alleviation (Mullholland 2018).

Underlying rural revitalisation is the state-led focus on cultural nationalism that has developed into a formidable force in China since the late 1980s and early 1990s: a cultural-political movement with no parallel in the People's Republic of China (Guo 2007, abstract). The gravity of the focus on cultural nationalism is evident in President Xi Jinping placing the pursuit of 'a rural revitalisation strategy third in China's "New Vision of Development and Developing a Modernised Economy" during the $19^{\text {th }}$ CPC National Congress on October 18, 2017' (Mulholland 2018). It is in effect a central aspect of the promotion of 'neo-traditionalism ... "the deliberate revival and revamping of old cultures, practices, and institutions for use in new political contexts and strategies"' (Yang 2017, 3). Indeed, President Xi has 'declared traditional thought and culture the "soul" of the nation (Xinhua August 8, 2016 in Yang 2017, 3). It is a sentiment further emphasised in Xi's view that 'Outstanding traditional culture is a country and nation's basis for continuation and development ... The prosperous development of Chinese culture is the prerequisite to the great rejuvenation of the Chinese nation.' (Yang 2017, 3-4)

Central to the process of revivalism is the critical role of the rural cultural landscape, its zeitgeist and meanings in Chinese culture. This proposition leads me to the next section of this paper which, perforce, starts with a brief overview of the terms 'space', 'place', and 'landscape'.

\section{Space, Place and Landscape}

Any landscape is a condition of the spirit. -Henri Frédéric Amiel

Corresponding with this quote is Relph's $(2008,30)$ observation that 'The spirit of a place lies in its landscape.' In both quotes 'spirit' has associational connections and meanings in the sense of spirit as 'the non-physical part of a person ... the seat of emotions and character; the soul.' $\left(\mathrm{OED}^{4}\right)$. In this way the abstract idea of spirit is inseparable from the intangibility of the accumulation of human memories and meanings-private and collective-and identity that we associate with the word 'landscape'. Focusing on landscape as a key word, perhaps the keyword, in my discussion inevitably brings into consideration inquiry into the meaning of the words 'places' and 'spaces' and their relationship to 'landscape.'

We are apt to interchange these three words 'space, place and landscape' and use them synonymously, when in fact, whilst linked, they have different associations (Mitchell 2002: Preface vii-xv, Tuan 1977). For Tuan (1977) space can be described as a location which has no social connections; no value has been added to it and no 


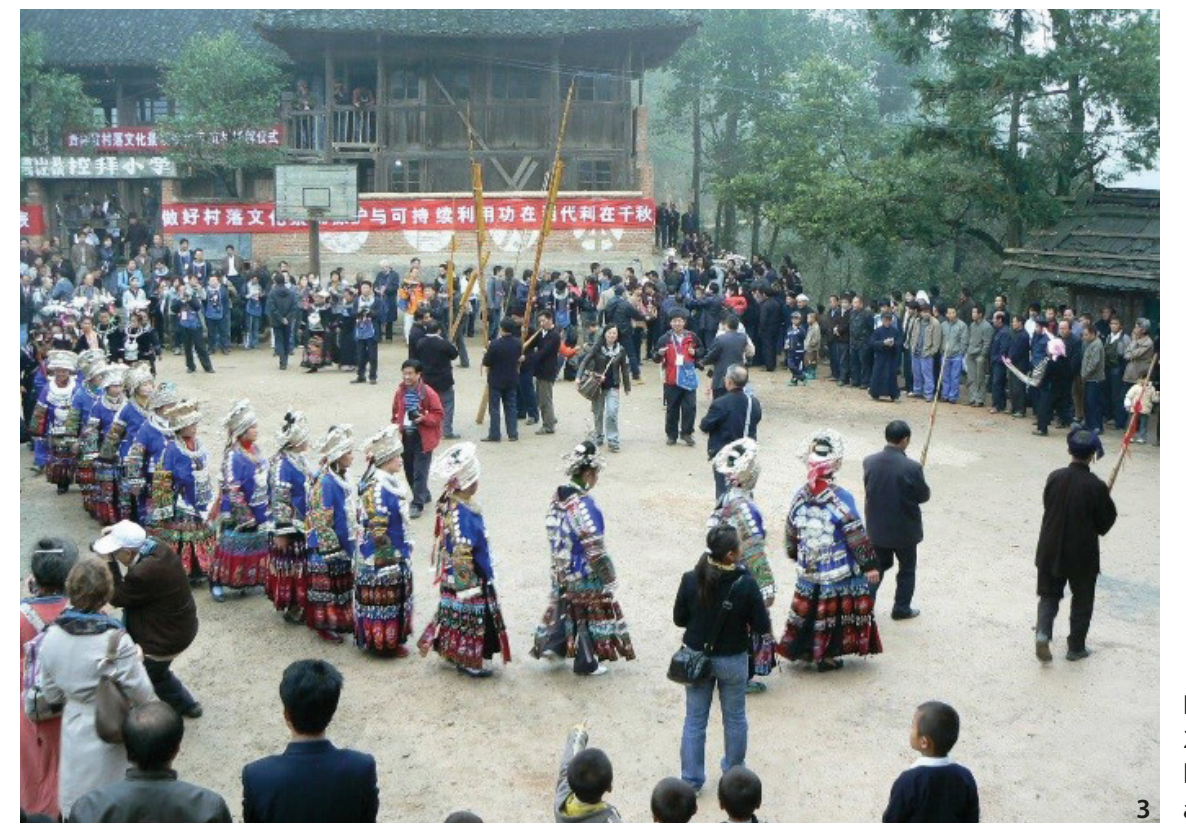

Figure 3 Kongbai Miao Village, Guizhou, 2008. Silversmithing village: space/place/ landscape setting relationship (Source: the author). meaning ascribed to it. It is more or less abstract. Nevertheless, there is a relationship between space and place in that spaces become places when given human connections and meaning, either through physical interaction or in indirect and conceptual, symbolic ways (Tuan 1977). Relph $(2008,8)$ portrays this as 'however we feel or know or explain space, there is always some associated sense or concept of place ... space provides the context for place but derives its meaning from particular places.' Tilley (1994, 15) dissects the space/place continuum as follows:

Space is a far more abstract construct than place. It provides a situational context for places, but derives its meaning from particular places (Relph 1976, 8) ${ }^{6}$. Without places there can be no spaces, and the former have primary ontological significance as centres of bodily activity, human significance and emotional attachment ... There may be strong affection for place (topophilia) or aversion (topophobia), but places are always far more than points or locations because they have distinctive meanings and values for persons. Personal and cultural identity is bound up with place ... (Figure 3)

Of relevance to this paper and the conference theme, the interwoven space-place-landscape interaction has been explored in a timely recent case study exercise 'Capturing Spatial Patterns and Traditional Rural Landscapes with 3D Point Cloud. Case Studies of Tunpu Villages in Guizhou Province' (CSP 2019). The exploratory work at Tunpu villages is set against the profound transitions that have and are taking place in traditional rural landscapes of China, noting inter alia that more than 900,000 villages disappeared in the decade from 2000 onwards (Feng 2013). Its basis is testing in the field a framework for mapping traditional rural landscapes using point cloud technologies. It is suggested that the approach recommended has implications for heritage management as a way of moving beyond site monitoring to dynamic management at three scales:

- Relationship between settlements and their natural setting.

- Village scale focusing on spatial pattern of individual villages as a built environment.

- Rural architecture.

The proposal that in effect here is another tool to assist positively in the development of conservation management plans for rural villages and their landscape setting is an important one.

To summarise, spaces and associated places reside in and cumulatively create the landscape where landscape is understood as a cultural construct. Here is the cultural landscape physically reflecting the process of landscape making through time replete with human associations anchored in values and meanings. It is a process where we can recognise successive layers in the landscape through time. We may therefore ask: 'What is landscape?' Here I am perversely reminded of Peter Howard's challenging suggestion that 'Landscape is not very rational' (Howard 2011, 2); a statement which he then perceptively deconstructs with the beguilingly profound yet simple and comforting observation that landscape 'is intensely personal and reflects our own history and culture, our personal likes and dislikes. It is always about "my place", or 


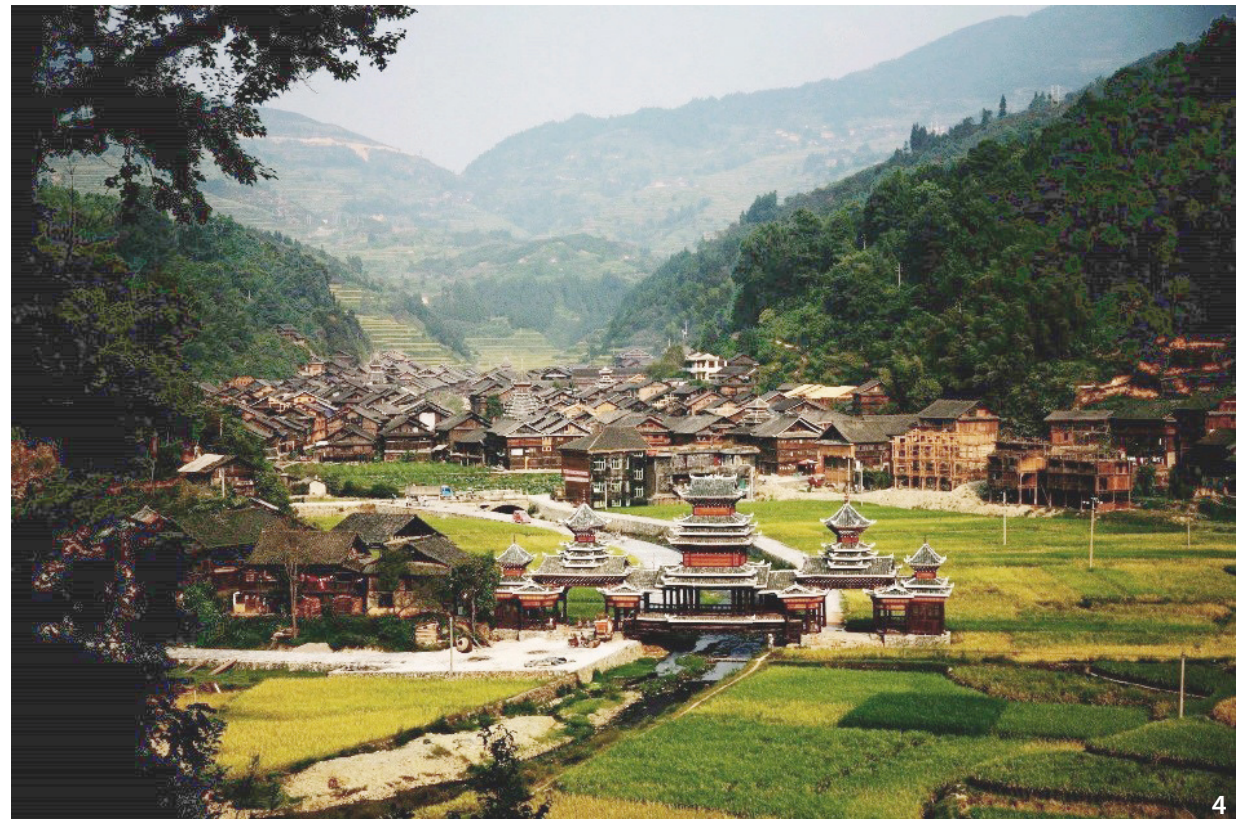

Figure 4 Zhaoxing, Dong Village, Guizhou (Source: Guizhou Zhaoxing Travel Guide, Chian Discovery) ${ }^{7}$. at least somebody's place.' This takes me to my next sectional topic.

\section{Landscape Is ...}

Julian Smith $(2010,46)$ linking place and landscape eloquently proposes that:

... it is useful to think of cultural landscapes as ideas embedded in a place, and to consider the recording of cultural landscapes as an exercise in cognitive mapping rather than physical mapping. The challenge of this approach is that a cultural landscape cannot be observed, it must be experienced. And it must be experienced within the cultural framework of those who have created and sustained it ...

People see and make landscapes as a result of their shared system of beliefs and ideologies (Biger 2006). In this way as Taylor $(2017 a, 23)$ has previously explored 'landscape is a cultural construct, a mirror of our memories and myths encoded with meanings which can be read and interpreted'. As J. B. Jackson so eloquently encapsulated the essential meaning of landscape as summarised by the pithy comment : 'A rich and beautiful book is always open before us. We have but to learn how to read it.' (Jackson 1951, 5)

Such a construct sits well with the idea of landscape as process where landscape is not simply a product of human endeavour, 'not as object to be seen or a text to be read, but as a process by which social and subjective identities are formed' (Mitchell 2002, 1). 40 years ago Meinig (1979,
1-3) proposed that 'Landscape is an attractive, important, and ambiguous term [that encompasses] an ensemble of ordinary features which constitute an extraordinarily rich exhibit of the course and character of any society' and that 'Landscape is defined by our vision and interpreted by our minds.' In other words, to understand ourselves we need to look searchingly at 'landscapes as a clue to culture' (Lewis 1979, 15) - to read them-and our ordinary everyday landscapes at that, not just the national monuments and icons. Such ordinary landscapes are what Lynda Sexson (1982) nicely encapsulates as 'the ordinarily sacred' where people find a sense of the sacred in ordinary everyday places.

Places, therefore, are not isolated dots on a map separated spatially and temporally. They link into a coherent whole, the landscape, with its various layers created through time. In this sense we can recognise patterns of spatial organisation in the landscape (Figure 4) resulting from periods of landscape making which in turn reflect cultural traditions and human response to natural elements (Page, Gilbert and Dolan 1998; Taylor 2017b). Coincidental to this process is that place and landscape making promotes a powerful feeling of belonging, identity and sense of place. David Lowenthal $(1975,12)$ nicely expresses this with the view that: 'It is the landscape as a whole-that largely manmade tapestry, in which all other artefacts are embedded ... which gives them their sense of place.'

These various references to what landscape is (and is not) are at the foundation of modern landscape study where landscape is not looked on as simply a pretty picture or as a static text. It concerns 'the world we are living 
in' (Wylie 2007, 1) and essentially is the expression of landscape as cultural process. 'The connections, therefore, between landscape and identity and hence memory, thought, and comprehension are fundamental to understanding of landscape and human sense of place.' (Taylor 2017a, 23) In summary therefore I contend that linked to deliberations in cultural landscape study there are six key issues to consider:

1. Landscapes are a clue to culture (see also Lewis 1979): they tell a story that can be read, interpreted and experienced.

2. Existence of continuity in the landscape: they present a composite image (montage) rather than a separate dot on a map approach to heritage, i.e. everything is connected.

3. They represent inter-relationships between places, events, people and setting over time.

4. Existence of layers of change over time.

5. They are significant reminders of the past and present: they contain elements that are part of our collective and private memories.

6. They reveal social history and can arouse associative values (related to knowledge of past and current events, people and places) and interpretative values.

Continuing with Lowenthal's premise it is notable that, during the latter half of the 1980s and early 1990s, academic and professional interest in heritage studies came to embrace the cultural landscape concept. Landscape, it was increasingly realised, was a document of social history reflecting the interaction between people, events, places and time. At the same time, and by no means accidentally, scholarly and professional interest in landscape, particularly the immaterial associative aspects of landscape, ran parallel with a shift away from an over concentration on physical aspects ${ }^{8}$ of heritage places to include an understanding of the significance of the intangibility of heritage. There emerged, in effect, a manifesto for a move to a refreshed way of thinking and acting where heritage and landscape began philosophically to sit 'comfortably together' (Harvey 2015, 911). That links exist between landscape and heritage is quite clear and we may, therefore, ask where and how does the concept of cultural landscapes slot into thinking on changing perspectives in heritage? (see Taylor 2017a for an extended discussion). Harvey $(2015,911)$ in this regard observes that:

The recent histories of heritage and landscape studies appear to be closely linked, with their epistemological, ideological and methodological twists and turns progressing amid a common broad intellectual and interdisciplinary space ... Heritage and landscape are two concepts that appear to have sat comfortably together within academic, policy and popular imaginations for some time.

In the context of the global synergy between the histories of heritage and landscape studies, it is no accident that Chinese engagement with rural revitalisation-with some focus on national historical and cultural villages and their landscape settings-has paralleled the country's increasing participation in global heritage practice underscoring the perceived link between culture and national identity. Importance is also attached to Chinese cultural self-confidence where culture acts as an economic agent. Within this sequence of events is the view that the countryside is a bastion of Chinese traditional culture where rural landscape is seen as being commensurate with national cultural confidence and identity. Landscape becomes a leitmotif for the integration of economic development, ecological and natural environment conservation, traditional Chinese culture, and development of tourism (Taylor and $\mathrm{Xu}$ 2019). This observation takes me logically to my next discussion point.

\section{A Chinese Perspective on Cultural Landscape}

Some years ago my esteemed colleague, Professor Feng Han, proposed that the term 'cultural landscape' was a tautology for the Chinese (Han 2004) with the term 'cultural' being redundant. For the Chinese mind all landscape is cultural. As Greffe $(2010,1)$ commented-aptly in my view-'we may wonder if there are really any landscapes that are not cultural.' Han (2006 and 2012) has enlarged on the underlying cultural meanings of landscape in China contrasting these with Western notions (N.B. these are in brackets), noting, inter alia, that it is humanistic (not religious), aesthetic (not scientific), nature is subjectively constructed (not objective in origin), travelling in nature aims to be enjoyable (not solitude oriented). Chinese landscape is, therefore, a place for religious thought, poetic dwelling, elite education, travelling, as well as a symbolic view of the world that is both material and spiritual $(\mathrm{Xu}$ 2017a). Inherent also is the indissoluble binary between culture and nature. The Chinese view-reflecting a shared philosophy common throughout Asia-is that people are part of nature, concisely captured in the reflection by Liu:

Nature and a view of nature, of course they are not the same thing ... there is only one nature and we are all part of it ... views of nature differ among different individuals, nations and cultures ... A view of nature is 
how nature is presented in one's subjective consciousness. Generally speaking, the view of nature most symbolises Chinese culture. (Liu 1991 as cited in Han 2012, 92)

Whilst these views on landscape are reflective of the Han Chinese majority (92\% of the population), it is important to note that China's ethnic minority cultures also have distinctive views of nature and landscape value systems, which have gradually merged with Han culture. For Chinese ethnic minorities, the relationship between nature and humans is the philosophical basis of national culture; nature is the origin of the universe, humankind and nation alike. The cultural construction of landscape for different Chinese ethnic minorities is related to their survival, lifeway, habitat and beliefs. It is a world of divinities, worship of objects and religious places, a living space, the source of national art, and a means of transmitting cultural traditions such as festivals and celebrations (Xu 2017b).

\section{Global Shifts in Heritage Thinking: Situating Village Renewal Examples, Guizhou Province}

\section{Whose Cultural Values?}

The case studies to which I will refer focus primarily on Miao and Dong settlements where cultural landscape changes with associated heritage management implications are taking place under the aegis of tourism development policies, strategies for sustainable rural development and poverty alleviation goals: e.g. through growing new cash crops such as tea or sphagnum for flower market use. In this equation how do we appraise the potential role of 'sustainable transformation of traditional villages' (Verdini, Frassoldati and Nolf 2017, 321) given that such transformation can be accompanied by unprecedented developments that can inexorably change the inherent character and traditional cultural diversity of such communities? In order to situate discussion on the case studies it is useful first to see these through the lense of changes in international thinking on cultural heritage. Germane to these considerations are questions of what are the limits of acceptable change and associated changes to authentic sense of place? Indeed, we may ask what is meant by 'authentic sense of place' given the observation (Verdini, Frassoldati and Nolf 2017, 319-320) that China in its engagement with international heritage practice has on the one hand conformed to such practice, yet managed 'contextually to retain its own identity [at the same time as] formulating a divergent approach especially around the notion of authenticity.' These concerns raise the thorny issue of what changes are acceptable, and whose cultural values are at stake?

The proposition of change inevitably suggests we need to explore what the historian Samuel in Theatres of Memory (1994) called 'the social role of heritage' (Harrison 2010, 241). Here Samuel saw heritage as serving 'to make the past more democratic through an emphasis on “ordinary" people.' (Harrison 2013, 100). At this point it is interesting to note that coincidentally in the field of heritage the rise of cultural landscapes was well under way and that 1992 saw the three categories of World Heritage cultural landscapes introduced by UNESCO ${ }^{9}$ and 1994 saw ICOMOS publish The Nara Document on Authenticity (ICOMOS 1994) which challenged conventional thinking in the conservation field. In its preparation recognition was paid to the framework provided by the World Heritage Committee's desire to apply the test of authenticity in ways which accord full respect to the social and cultural values of all societies.

Here we see notions of heritage shifting from the 1970 s and early 1980s over-emphasis on famous monuments and sites (tangible heritage) to an understanding of the rich diversity of cross-cultural meanings of heritage places and human associations with such places (intangible cultural heritage). For the purposes of my paper there is little doubt in my mind that the increasing interest in, and understanding of, the cultural landscape construct played a not insignificant role in this shift. This is not least so because of scholarly interest in the link between cultural landscapes and the ordinary everyday places that people have created over time in which heritage values in here. Here, cultural heritage thinking and practice embraced and built on the innovative work of cultural geographers (Taylor 2012). It is important to remember also in this connection that landscape and culture are not static. They change over time as cultural values change, not just in response to internal cultural forces, but in response to external forces in which, for example, tourism (see below) is a major force alongside social and economic policies as in China's rural revitalisation program. Correspondingly such changes also affect the way that:

The meaning of heritage will vary over time and for different groups of people. It serves social, cultural and political functions. But the heritage during this process does not remain static and unchanged ... We use the heritage in the creation of our own individual, group and national identities. (Uzzell 2009, 326-327) 
In turn and linked to this has been and remains so the critical discourse that has taken place on the concept of living history/living heritage link to the cultural landscape concept (Taylor and Altenburg 2006). Changing ideas on living history and living heritage and history/heritage from below are also reflected in various international heritage initiatives such as ICCROM 2000 Promoting People Centre Approaches to Conservation: Living Heritage ${ }^{10}$; ICOMOS 2005 Filling the Gaps; UNESCO 2007 World Heritage Challenges for the Millennium; UNESCO 2007; 'Community' added as fourth 'C' to Credibility, Capacity Building, Communication in the 2002 Budapest Declaration on World Heritage; UNESCO World Heritage Papers: 26 (2009) on Cultural Landscapes; Papers 31 (2012) on Community Development and World Heritage; Papers 41 (2014) on Engaging Communities in Stewardship of World Heritage.

The shift that has occurred in thinking on living history/living heritage is part of the re-orientation of the 'conventional' (Wijesuriya, Thompson and Young 2013) cultural heritage management approach from solely caring for the physical fabric of heritage structures, towards recognising the significance of intangible cultural heritage and associated values of living communities and the needs and wishes of living communities who are the custodians of this heritage. Putting them centre-stage, the thinking goes, ensures a more engaged, better informed and locally rooted conservation management process, which is more culturally sustainable. Poulios (2014, 28-29) expresses this in his three key principles that determine a 'living heritage approach':

1. Recognising local communities as the true long-term custodians of their heritage sites;

2. Empowering communities in the conservation and management process, and benefiting from their traditional knowledge, management systems and maintenance practices; and

3. Linking conservation to the sustainable development of the communities, by developing a process to manage change and by making heritage relevant to the needs of the contemporary communities.

\section{Tourism}

Notably in tracing the officially sanctioned development of tourism in Guizhou with an ethnic minorities focus from the 1980s onwards Oakes $(1997,36)$ suggests that:

... the process of commercial and cultural integration associated with tourism does not necessarily break down a place-based sense of identity or render it flat and inauthentic; instead, it becomes an important factor in the ongoing construction of place identity. Place-based identity is built according to a broader set of political, economic, and cultural processes rather than in relative isolation from those processes. In many places in Asia, tourism has rapidly become a powerful example of these broader processes, injecting a new set of conditions into local expressions of identity and sense of place. Even on the frontiers of tourism in Asia, locals have quickly learned to appropriate the tourist experience in their claims of place identity.

Oakes $(1997,37)$ further reflects that ethnic identity has become officially associated with state mediated processes which:

provide much of the raw material ... that locals use to claim a distinct place identity. Even as tourism introduces processes that increasingly link villagers to the outside world, threatening to dislocate and alienate them, it simultaneously allows them to continue the ongoing redefinition of place in new terms.

It is in these contexts that we have to see the ethnic village renewal examples I use. They are representative of the everyday, ordinary places and the cultures that have made them over time and continue to make and remake. They present irresistible attractions for tourists, domestic and international, not least their exotic allure. William Nitzky $(2013,212)$ sees this allure linked to 'China's cultural revitalisation since the 1980s and cultural heritage industry boom', also noting that 'ethnic minorities' "exotic" cultural traditions have attracted much attention for practices of preservation $[\text { sic }]^{11}$, as well as processes of commoditisation.' Recognition of cultural heritage-and not least intangible cultural heritage-has been an integral component of the development of Guizhou's cultural industry where 'heritage has even become a form of cultural and intellectual property' (Nitzky 2013, 213). Heritage presentation for tourists reflects how 'Authentic intangible cultural heritage $(\mathrm{ICH})$ provides a community with a unique selling point in the globally competitive tourism industry ... [and] is fast becoming a significant resource in cultural heritage tourism.' (Kim, Whitford and Arcodia 2019, 1). Here one may question what is meant by 'authentic', with authenticity recognised now as not being simply rooted in the physical fabric of heritage places, but applying to $\mathrm{ICH}$ and thereby susceptible to change through time in response to changing conditions, including tourist expectations; Stovel $(2007,28)$ refers to the phenomenon of change as 'progressive authenticity.' Further, Yan (2017) 

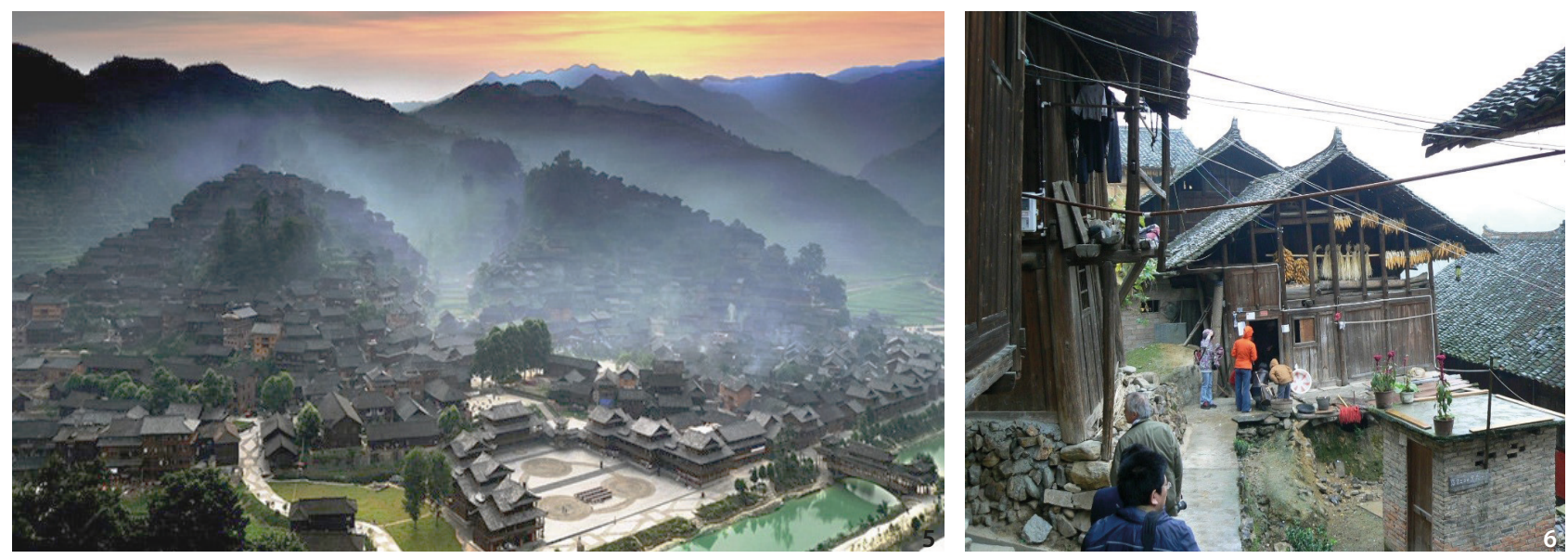

Figure 5 Xijiang Miao Village (Source: https://www.chinadiscovery.com/guizhou/kaili/xijiang-miao-village.html). Figure 6 Xijiang Miao Village stilt housing in 2008 (Source: the author).

suggests that in China heritage, tourism and identity are inextricably linked and that heritage with its connections to people's different lived experiences and potential for meaning and identity is used as part of the process of national identity building.

On the role of heritage, Harrell (2013) claims heritage is not dead when change occurs - a claim with which I wholeheartedly agree-because heritage conservation itself is part of cultural change. He further proposes that 'the forms that emerge in the intentional process of preservation [sic] are just as much links in the chain of cultural continuity as are the forms that emerge out of less self-conscious and more organic processes' (Harrell 2013, 286). He pins his argument on the point that even where a tradition continues in whatever form, albeit changed, it can be worthwhile, noting that traditions change anyway, even when left alone. He does however indicate that change as a result of an organic process through time and change brought about by heritage protection are different.

In the examples I use it can be seen that overall landscape setting-countryside-is a critical aspect of the sense of place of the villages. Interestingly 'picturesque landscape' is one of the criteria used to select ethnic tourist sites by Qiandongnan's tourism bureau (Oakes 1997).

\section{Xijiang Thousand Household Miao Village (Qian- dongnan Autonomous Prefecture)}

The eight original constituent villages of Xijiang occupy a series of steep hills on both sides of a river valley (Figure 5) with the traditional three-storey stilt-houses cascading picturesquely down the slopes bordered by native forests and agricultural plots (rice paddies, vegetables and wheat) (Figure 6). Some 10 years ago (2008) there were about 1,200 families living there with a population of over 5,000 people. A joint policy by national and provincial governments in the early 2000s saw financing of various developments aimed at deterring rural migration to urban areas, diversification of employment opportunities, support for local crafts including silver-smithing and textile production, encouragement for the continuation of ethnic traditions such as festivals and celebrationsdancing, singing and traditional foods-and the opening up of tourism opportunities.

By 2008, Xijiang had a tourist lookout atop one of the hills giving a panoramic view of the landscape setting, a central outdoor performance space specifically for dance and music performances (Figure 7) and an eco-museum built by locals housing traditional textiles and everyday goods such as baskets and silver jewellery. Also, two new streets of timber houses had been built to provide shops in an architectural style reflective of the local vernacular. To support these initiatives, major transport infrastructure projects in the region have made the area accessible and tourists-national and international-have come in increasing numbers. In 2008 a foreign expert expressed concern at the developments then occurring, not least the central dance and performance square where shows for visitors could be seen to corrupt and falsify the authentic, traditional meaning of the dances and music. Do they?

Since 2008, more changes have occurred including the addition of an international style hotel and extensive car parking outside the village, and the proliferation of new guest houses, bars and more shops. There is now a new visitor entry area with turn-styles, shops, and gaudy electronic advertising screens, an entry charge of $100 \mathrm{CNY}$, and $20 \mathrm{CNY}$ for mini-buses from and to the new entry point. These changes have seen the influx of outsiders 

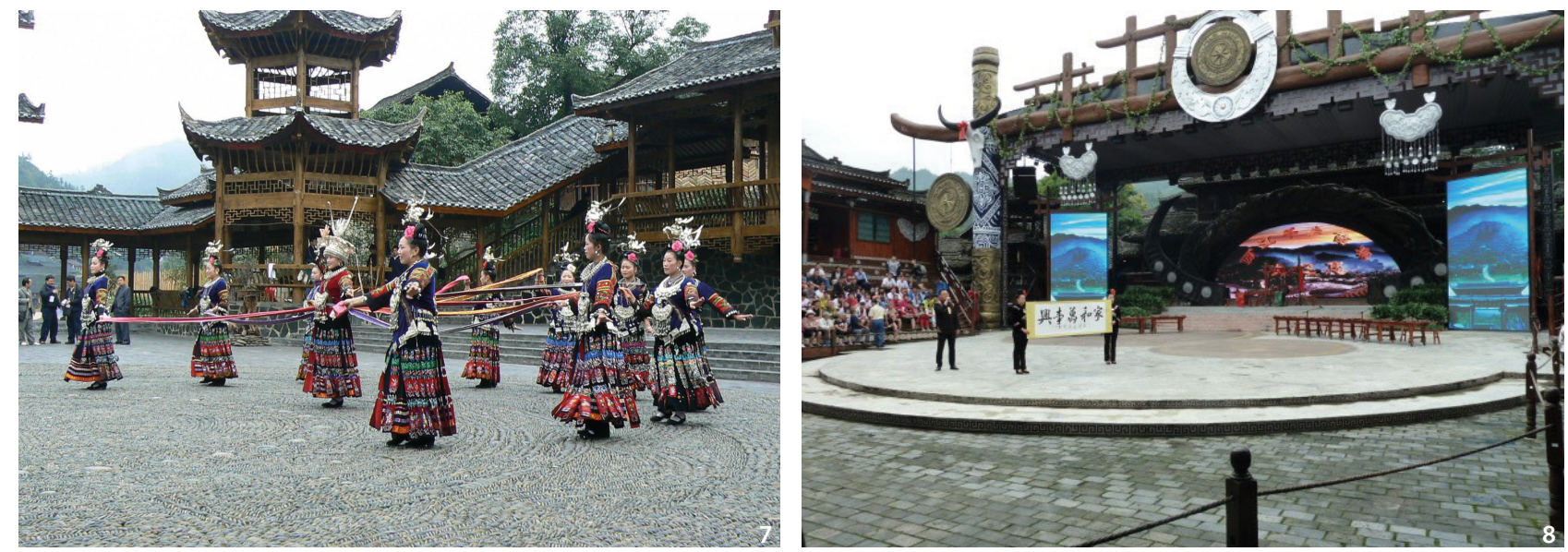

Figure 7 Xijiang Miao Village performance area 2008 (Source: the author). Figure 8 Xijiang Miao Village performance arena 2017 (Source: the author).

who have come to share in the new economic opportunities encouraged by tourism. It is estimated that the local population has increased to around 20,000, with many of these operating the new guest houses, shops and bars. It is a matter of opinion whether the success of the government initiated changes aimed at encouraging tourism and the consequences of associated growth have negatively affected Xijiang's character and sense of history in the landscape. Tourism is rampant, irrevocably changing Xijiang's physical character. The 2008 lookout is now a space where tourists can dress up for photographs wearing hired Miao costumes. The open-air performance space has been replaced by an auditorium (Figure 8), with an additional entry charge, where tourists watch locals perform. The auditorium has tiered seating and a stage where announcers' voices-backed by more gaudy electronic screensboom out through microphones and loudspeakers. In 2008 the number of visitors was close to 700,000 , it is now more than 3 million.

\section{Zhaoxing Dong Village, Liping County, Guizhou}

Zhaoxing, the largest and oldest Ethnic Dong Village (Figure 4), has a distinctive landscape setting in a steep sided valley basin. It has long been regarded as a true, authentic representative of Dong ethnicity and since tourism got underway in the mid-1990s locals have been encouraged to express a sense of place incorporating this ideal of authenticity, an ideal conditioned by Zhaoxing's links to the broader commercial tourism and culture industries (Oakes 1997, 64). Estimated to receive more than 3 million tourists per year there is still a sense of place and links with the culture's past brought into the present day in a mix of the old and the new. Examples include the renovated main street (Figure 9); landscape setting; new cafés/bars; five reconstructed traditional drum towers destroyed during the Cultural Revolution (Figure 10); outdoor theatre; older area/housing along the river (Figure 11); traditional wind and water bridges which are maintained or rebuilt if badly flood damaged; one use of these is gathering places for older residents reflecting significant social and cultural values. But behind this image as tourism has brought financial benefits there are tensions such as a preference now by locals to build concrete or masonry houses albeit with a veneer of timber. As Yating Zhou , in charge of the town's party affairs reflected in 2013 on the economic benefits of tourism but also the dilemmas it has caused: 'Now that people's lives are getting better, they want to live in concrete houses.' (Figure 12) (Hruby and Wang 2016). Underlying this kind of dilemma is the challenge of what are the acceptable levels of change both materially and culturally and coming to terms with the relationship between tourism and local identity. Here Oakes (1997, 66) suggests:

The experience of tourism becomes a fundamental component of people's senses of place and ethnic identity [in which] a commercial tourist industry driven by the ideal of cultural authenticity [has resulted in] local identity ... conditioned by a dynamic tension between extra local forces and local traditions. Tourism is the latest (and probably most intense) manifestation of these broader forces to become appropriated by a local cultural discourse of identity and meaning.

Here Oakes argues that tourism is not necessarily 'an outside force that "flattens" culture' (Oakes 1997, 35) and replaces it with something that is superficial and 

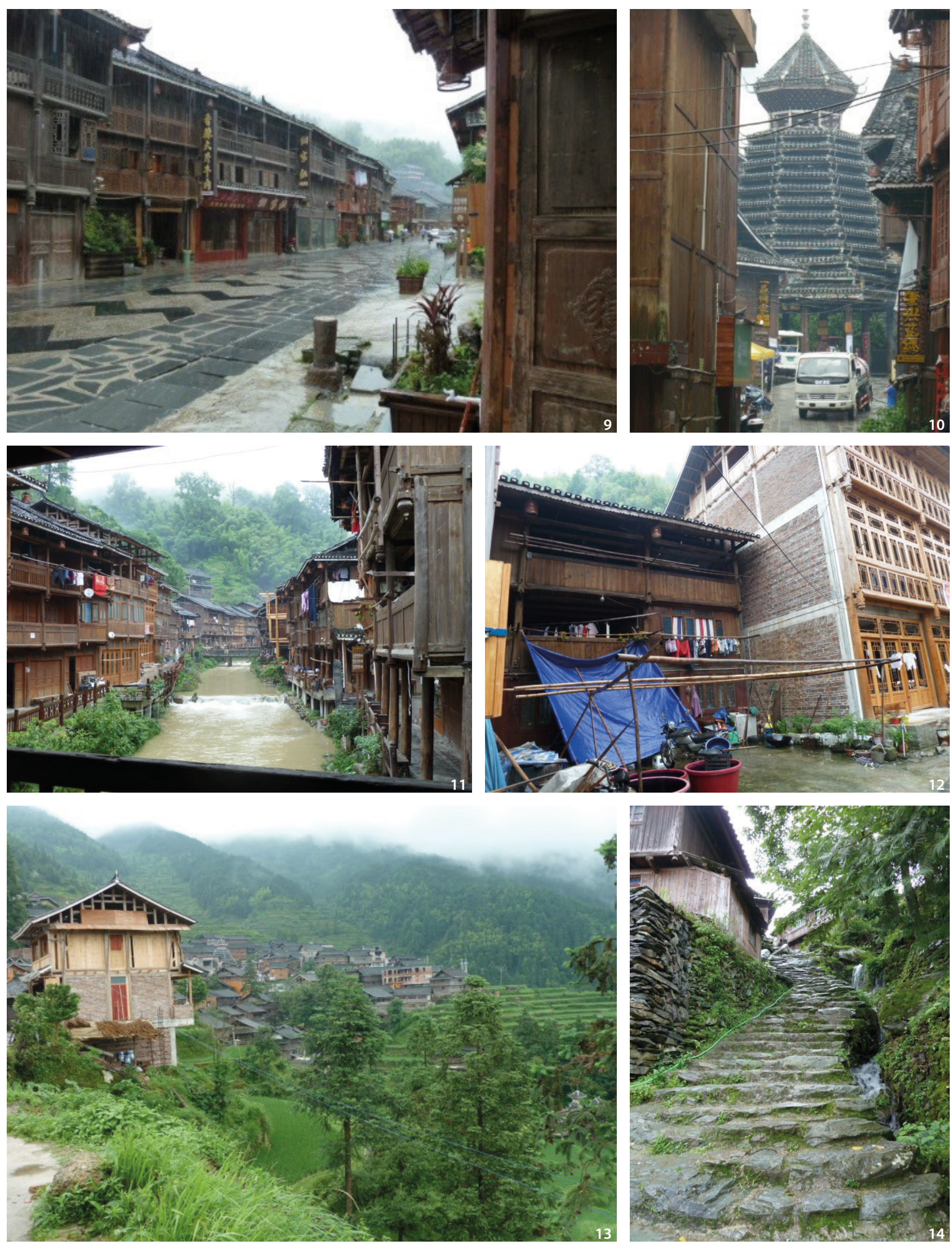

Figure 9 Zhaoxing Dong Village redeveloped main street 2017 (Source: the author).

Figure 10 Zhaoxing Dong Village Drum Tower 2017 (Source: the author).

Figure 11 Zhaoxing Dong Village old street 2017 (Source: the author).

Figure 12 Zhaoxing Dong Village new housing 2017 (Source: the author).

Figure 13 Tang'an Dong Village landscape setting 2017 (Source: the author).

Figure 14 Tang'an Dong Village character 2017 (Source: the author). 


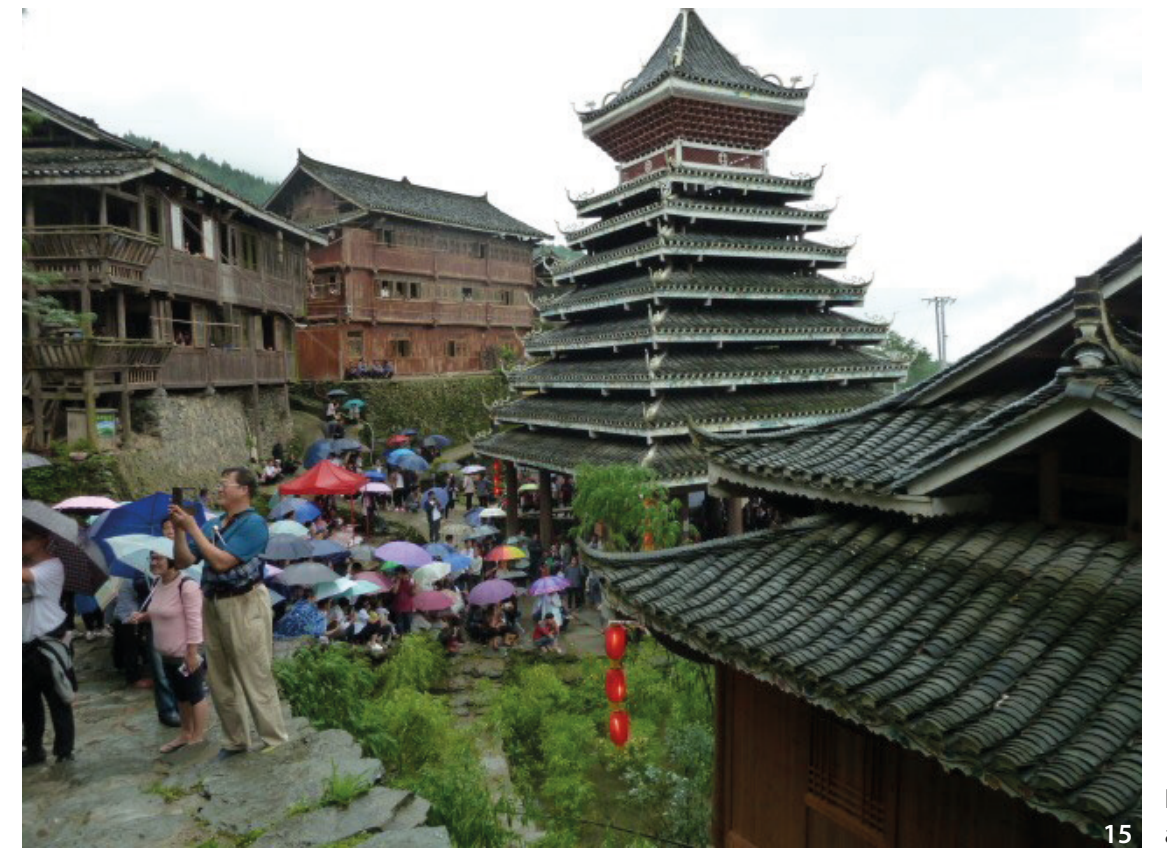

Figure 15 Tang'an Dong Village Drum Tower and opera stage 2017 (Source: the author).

inauthentic. I suggest here that it is within these parameters that we need to consider tourism and its effects as it relates to the cultural context of traditional social groups whether they be ethnic minorities or not. We need to look long and hard at how local people express who they are and what are their cultural values, acknowledging that cultural diversity 'is an irreplaceable source of spiritual and intellectual richness' as expressed by The Nara Document on Authenticity (ICOMOS 1994) a quarter of a century ago and that culture and cultural values change in time and space.

\section{Tang'an Dong Village}

The distinctive sense of place and identity clearly evident at Tang'an (Figure 13) with its relatively remote settingoff the beaten track as it were-stands in some ways perversely as both a contrast to, and comparison with, Xijiang and Zhaoxing. This is particularly so when viewed in the context of the contested topic of authenticity, prompting the question, have remoter villages such as Tang'an maintained a greater degree of authenticity? Are they 'much less spoiled, more traditional'? (Oakes 1997, 55). Certainly Tang'an has this 'feel' to it nestling amongst terraced rice paddies which cascade down the slopes and along the serpentine valley winding towards Zhaoxing, thereby creating a skilfully engineered landscape almost like an abstract painting. Inside the village the all-pervading intangible feeling and sense of place continue (Figure 14).

To distinguish Lang'an and create a distinctive brand image as a tourist attraction it is referred to as Tangan
Dong Ethnic Eco-Museum and marketed as the place to visit 'if you want to experience the authentic Dong people's life in China, Tang'an Dong Ethnic Eco-Museum (Tang'an Dong Village) is a choice destination. ${ }^{12}$ It is described as a living open-air museum 'where the Dong live in perfect harmony with each other but also with nature ${ }^{13}$ with attractions such as rice terraces, diaojiaolou (stilting houses), drum towers and ancient opera stages (Figure 15), wind and rain bridges, ancient tomb clusters, stone wells and water wheels. We may ask what is it at Tang'an that evokes a special sense of place and a 'sense of feeling' (Zhang and Taylor 2019) prompted as it is by the emotional response to the place that represents a spirituality. It is in effect an associative response to place, one knows it is there, it exists as an intangible force, but is difficult to express in words. Cameron and Gatewood (2003) refer to this quality as 'numinous', something that displays a strong spiritual quality reflecting intangible heritage associations and memories reflecting evocatively how we envisage a memorable place and its cultural landscape setting. In relation to setting, Tang'an is at the head of a picturesque valley (Figure 13), it is the end destination, not on the way to somewhere else, a quality which seemingly increases its attraction.

\section{Conclusion}

The influence and challenge of political and economic policies and priorities and their effect on heritage conservation and related aspects of landscape management cannot be ignored. In particular, there is the policy of 
alleviating poverty in rural areas, which is a phenomenon of all levels of government: local, provincial and national. A key policy area has been and remains encouragement of tourism. Heritage sites are seen as economic resources with the pursuit of economic development a primary goal. In the case of places like Xijiang, it is easy to judge the rampant development that has taken place as crass and destructive of Miao culture. But do the locals see it in this vein when they have income from heritage tourism that sustains them, allows them to fund schooling for children and brings jobs? Indeed, in Xijiang and other villages there is some involvement of local people and communities in tourism management. If we accept that culture is created by local people and is not static, then who am I to criticise change that takes place? One thing is certain, and that is that culture changes and will continue to do so both in spite of management actions as well as because of them. In looking at such change we must try to understand the views, opinions and hopes of local people and ponder on the quotation with which I headed this paper: 'We should never tinker with the landscape without thinking of those who live in the midst of it' (Jackson 1963, 2). Further, in this connection I am reminded of the following powerful and pithy observation by Atticus Finch in the Harper Lee novel To Kill a Mocking Bird: 'You never really understand a person until you consider things from his point of view ... until you climb into his skin and walk around in it.'

This is not to suggest that in managing rural heritage places we simply accept what local communities say, but their views must be taken into account.

\section{Notes}

1. The referred conference is the Second International Conference on Built Heritage Studies (BHS2019), held in Tongji University in April 2019 on the theme of Built Heritage Conservation in Rural Vitalisation.

2. For example, by 1970 Fairbrother records that there were 1,300 known deserted villages in 1970 in the Midlands/eastern lowland area of Britain.

3. Swiss philosopher and poet, 1821-1881.

4. OED; Oxford English Dictionary.

5. In this space/place binary Relph proposes various forms of space: Pragmatic, Perceptual, Existential, Architectural, Cognitive.

6. Relph 1976 is an earlier version of Relph 2008.

7. https://www.chinadiscovery.com/guizhou-tours/ zhaoxing-tours.html (Accessed 21 June 2019)

8. Known as 'conventional' approach to cultural heritage management.
9. The three categories of cultural landscapes for World Heritage purposes are: (i) Clearly defined landscape designed and created intentionally by man; (ii) Organically evolved landscape which may be a relict or fossil landscape or a continuing landscape which retains an active social role in contemporary society associated with traditional way of life and in which the evolution process is still in progress (it is the continuing landscape that is most common and its adoption opened up the WH listing process to everyday landscapes/places that otherwise would not be nominated); (iii) associative cultural landscape justified by virtue of its powerful symbolic, artistic or cultural association of the natural element rather than material cultural evidence.

10.http://www.iccrom.org/priority-areas/living-heritage/ (Accessed 21 June 2019)

11. N.B. the term 'preservation' is used in the US, whereas internationally the preferred term 'conservation' is common practice in reference to the overall process of looking after a heritage place whilst 'preservation' is a specific action.

12. Absolute China Tours. http://www.absolutechinatours. com/china-gallery/gallery-tangan-dong-village.html (Accessed 21 June 2019)

13. China Escapade. http://www.chinaescapade.com/travel-guide/liping/hike-zhaoxing-tangan.html (Accessed 21 June 2019)

\section{References}

Biger, Gideon. 2006. "Introduction: Ideology and landscape." In Ideology and Landscape in Historical Perspective, edited by Alan R. H. Baker and Gideon Biger, 1-14. Cambridge: Cambridge University Press.

Cameron, Catherine, and John B. Gatewood. 2003. "Seeking Numinous Experiences in the UnrememberedPast.” Ethnology 42 (1): 55-71.

CSP (Capturing Spatial Pattern). 2019. "Capturing Spatial Patterns and Traditional Rural Landscapes with 3D Point Cloud. Case Studies of Tunpu Villages in Guizhou Province." Unpublished article.

Fairbrother, Nan. 1970. New Lives, New Landscapes. London: The Architectural Press.

Feng, Jicai. 2013. “The Problem and Solution of Traditional Villages-Traditional Village in Another Category of Cultural Heritage." [Chuantong cunluo de kunjing yu chulu-jian tan chuantong cunluo shi lingyizhong wenhua yichan] Forum on Folk Culture, no. 1: 7-12.

Greffe, Xavier. 2010. "Urban Cultural Landscapes: An Economic Approach.” EBLA Working Papers 201001. 
University of Turin.

Guo, Yingjie. 2007. “The Revival of Chinese Cultural Nationalism." Portal Journal of Multidisciplinary International Studies 4 (1):1-7.

Han, Feng. 2004. "Cross-cultural Misconceptions: Application of World Heritage Concepts in Scenic and Historic Interest Areas in China." Paper presented at 7th US/ICOMOS International Symposium, New Orleans, LA, 25-27 March.

Han, Feng. 2006. "The Chinese View of Nature: Tourism in China's Scenic and Historic Interest Areas." PhD diss., Queensland University of Technology.

Han, Feng. 2012. "Cultural Landscape: A Chinese Way of Seeing Nature." In Managing Cultural Landscapes, edited by Ken Taylor and Jane Lennon, 90-108. Abingdon \& New York: Routledge.

Harrell, Stevan. 2013. "China's Tangled Web of Heritage." In Cultural Politics in China, edited by Tami Blumenfield and Helaine Silverman, 285-294. New York, Heidelberg, Dordrecht, London: Springer.

Harvey, David. 2015. "Landscape and Heritage: Trajectories and Consequences." Landscape Research 40 (8): 911-924.

Howard, Peter. 2011. An Introduction to Landscape. Farnham: Ashgate.

Hruby, Denise, and Lianzhang Wang. 2016. "Tourism Traps Ethnic Minority in Tradition." Sixth Tone, September 13. Accessed 1 March 2019. http://www.sixthtone.com/news/1326/tourism-traps-ethnic-minorityin-tradition/

Jackson, John Brinckerhoff. 1963. "Goodbye to Evolution." Landscape 13 (1): 2.

Jacques, David. 1995. “The Rise of Cultural Landscapes." International Journal of Heritage Studies 1 (2): 91-101.

Kim, Soojung, Michelle Whitford, and Charles Arcodia. 2019. "Development of Intangible Cultural Heritage as a Sustainable Tourism Resource: the Intangible Cultural Heritage Practitioners' Perspectives." Journal of Heritage Tourism. Advance online publication.

Lewis, Peirce. 1979. "Axioms for Reading the Landscape: Some Guides to the American Scene." In The Interpretation of Ordinary Landscapes: Geographical Essays, edited by Donald W. Meinig 11-32. New York: Oxford University Press.

Liu, Xiaofeng. 1991. "There are People in the Empty Mountains-Reading the 'Chinese Literati's View of Nature"' [Kong shan you renji-du zhongguo wenren de ziran guan duanxiang].https://www.godoor.net/ text/wenhua/sixiang26-9.htm
Meinig, Donald, W. 1979. “Introduction.” In The Interpretation of Ordinary Landscapes: Geographical Essays, edited by edited by Donald W. Meinig. New York: Oxford University Press.

Mitchell, W. J. T., ed. 2002. Landscape and Power. 2nd ed. Chicago: Chicago University Press.

Mulholland, Jamie. 2018. "Xi Jinping's Rural Revitalization Strategy." China.org.cn. Accessed 2 Janurary 2019. http://www.china.org.cn/opinion/2018-03/15/content_50711502.htm

Nitzky, William. 2013. "Community Empowerment at the Periphery." In Cultural Politics in China, edited by Tami Blumenfield and Helaine Silverman, 188-232. New York, Heidelberg, Dordrecht, London: Springer.

Oakes, Tim. 1997. "Ethnic Tourism in Rural Guizhou: Sense of Place and the Commerce of Authenticity." In Tourism, Ethnicity and the State in Asia and Pacific Societies, edited by Michel Picard and Robert Wood, 35-70. Honolulu: University of Hawaii Press.

Page, Robert, R., Cathy A. Gilbert, and Susan A. Dolan. 1998. A Guide to Cultural Landscape Reports: Contents, Process, and Techniques. United States. National Park Service. Park Historic Structures and Cultural Landscapes Program. Washington, DC: U. S. Dept. of the Interior, National Park Service.

Poulios, Ioannis. 2014. "Discussing Strategy in Heritage Conservation: Living Heritage Approach as an Example of Strategic Innovation.” Journal of Cultural Heritage Management \& Sustainable Development 4 (1): 16-34.

Relph, Edward. (1976) 2008. Place and Placelessness. London: Sage.

Sexson, Lynda. 1982. Ordinarily Sacred. Charlottesville: University of Virginia Press.

Smith, Julian. 2010. "Marrying the Old with the New in Historic Urban Landscapes." In World Heritage Papers 27 Managing Historic Cities, edited by Ron van Oers and Haraguchi Sachiko, 45-52. Paris: UNESCO World Heritage Centre.

Stovel, Herb. 2007 "Effective Use of Authenticity and Integrity as World Heritage Qualifying Conditions." City \& Time 2 (3): 21-36.

Taylor, Ken. 2012. "Landscape and Meaning: Context for a Global Discourse on Cultural Landscape Values." In Managing Cultural Landscapes, edited by Ken Taylor and Jane Lennon, 21-44. Abingdon \& New York: Routledge.

Taylor, Ken. 2017a. "Landscape, Culture and Heritage. Changing Perspectives in an Asian Context.” Deakin 
University Library, Australia. Accessed 1 March 2019. http://dro.deakin.edu.au/view/DU:30102152

Taylor, Ken. 2107b. "Role of Research in Understanding Cultural Landscape Meanings and Values." In Research in Landscape Architecture: Methods and Methodology, edited by Adri van den Brink, Diedrich Bruns, Hilde Tobi, and Simon Bell. Abingdon, UK \& New York: Routledge; 266-268.

Taylor, Ken, and Kirsty Altenburg. 2006. "Cultural Landscapes in Asia-Pacific: Potential for Filling World Heritage Gaps." International Journal of Heritage Studies 12 (3): 267-282.

Taylor, Ken, and Qing Xu. 2019. "Challenging Landscape Eurocentrism: An Asian Perspective." In The Routledge Companion to Landscape Studies, edited by Peter Howard, Ian Thompson, Emma Waterton and Mick Atha, 311-328. London and New York: Routledge.

Tilley, Christopher. 1994. "Space, Place Landscape and Perception: Phenomenological Perspectives." In $A$ Phenomenology of Landscape: Places, Paths and Monuments, edited by Tilley Christopher, 7-34. Oxford: Berg. http://ls-tlss.ucl.ac.uk/course-materials/ ANTH1001_74186.pdf

Tuan, Yi-fu. 1977. Space and Place: The Perspective of Experience. Minneapolis: University of Minnesota.

Uzzell, David. 2009 "Where is the Discipline in Heritage Studies? A View from Environmental Psychology." In Heritage Studies: Methods and Approaches, edited by Marie Louise Stig Sørensen and John Carman, 326333. Abingdon: Routledge.

Verdini, Giulio, Francesca Frassoldati and Chirstian Nolf. 2017. "Reframing China's Heritage Conservation Discourse: Learning by Testing Civic Engagement Tools in a Historic Village." International Journal of Heritage Studies 23 (4): 317-334.

Wijesuriya, Gamini, Jane Thompson, and Christopher Young. 2013. Managing World Cultural Heritage. Paris: UNESCO World Heritage Centre in association with ICCROM, ICOMOS, IUCN.

Wylie, John. 2007. Landscape. Abingdon UK \& New York: Routledge.

Xu, Qing. 2017a. "Research on Cultural Landscape Value System of Lushan Scenic and Historic Interest Areas." $\mathrm{PhD}$ diss. Tongji University.

Xu, Qing. 2017b. "A Study on the Conservation and Development of Cultural Landscape in the Poverty-stricken Areas of Ethnic Minorities in Southwest China - Based on the Interpretation of Cultural Landscape Value." China National Social Science Fund Project. 61-79.
Yan, Hongliang. 2017. Heritage Tourism in China. Modernity, Identity and Sustainability. Bristol: Channel View Publications.

Yang, Zi. 2017. "Xi Jinping and the Restoration of Traditionalism in China." AsiaNews.it. Accessed 15 February 2019. http://www.asianews.it/news-en/XiJinping-and-the-Restoration-of-Traditionalism-inChina-41252.html

Zhang, Rouran, and Ken Taylor. 2019. "Cultural Landscape Meanings: The Case of West Lake, Hangzhou, China." Landscape Research. Advance online publication. https://doi.org/10.1080/01426397.2019.1589438 